$\underline{\underline{p}}$

\title{
Early neurodevelopmental anomalies in young rats from adult female treated with valproic acid
}

\author{
Landry Martial Miguel ${ }^{1}$ *, Archange Emmanuel Mboungou Malonga ${ }^{1}$, Didier Gesril Njilo Tchatchouang ${ }^{1}$, \\ Childérick Lékana ${ }^{1}$, Choupette Ravelle Dobhat-Doukakini ${ }^{1}$, Emmanuel Grace Nkounkou Matondo ${ }^{1}$, \\ Ruphin Bertrand Bolanga ${ }^{1,2}$, Donatien Moukassa ${ }^{1,3}$, Ange Antoine Abena ${ }^{1,4}$ \\ ${ }^{1}$ Experimental and clinical neuropathology unit, Faculty of Health Sciences, Marien Ngouabi University, Brazzaville, Republic of \\ Congo \\ ${ }^{2}$ Hematology laboratory, Public Health National Laboratory, Brazzaville, Republic of Congo \\ ${ }^{3}$ General Hospital Edith Lucie Mbongo Ondimba, Oyo, Republic of Congo \\ ${ }^{4}$ Dénis Sassou N'Guesso University, Brazzaville, Republic of Congo \\ *Corresponding authorE-mail: miguel_landry@yahoo.fr
}

\begin{abstract}
Background: the influence of VPA on murine fertility, and on offspring is well documented: VPA decreases the fertility rate (by $25 \%$ ) and the number of fotus. Furthermore, VPA causes behavioral alterations in rodents similar to the symptoms observed in autism. Objective: in this study we investigated the effects of exposure of non-pregnant adult rats to VPA in the offspring of these animals. Material and methods: non-pregnant adult rats were divided into 3 groups; (1) distilled water group, (2) VPA $200 \mathrm{mg} / \mathrm{kg}$ group and (3) VPA $400 \mathrm{mg} / \mathrm{kg}$ group. The products were administered orally daily for 30 days. At the end of treatments, all rats were put into monogamous mating with breeding males. The zootechnical characteristics (gestation period, litter size, mortality rate) were then noted. The young rats were then subjected to a battery of behavioral tests (reversal and anti-gravity reflexes, cliff avoidance, suspension, motor coordination and eye opening), carried out at different stages of life to assess sensorimotor development. Morphological abnormalities were also sought, as well as the mortality rate on the 28 th day of life.

Results: An increase in the mortality rate and a decrease in the mean lifespan were found in female rats exposed to VPA. Young rats from female rats exposed to VPA showed decreased success rates and performance in behavioral testing. Morphodevelopmental abnormalities such as adictalia or stump necrosis were found in the VPA groups. The offspring mortality rate of female rats exposed to VPA $200 \mathrm{mg} / \mathrm{kg}$ was $100 \%$.

Conclusion: VPA administered to non-pregnant adult rats causes developmental abnormalities, decreased success rates for performance testing, deformities and increased mortality in young rats from the treated rats by VPA.
\end{abstract}

Keywords: Valproic Acid; Rat; Sensorimotor Development; Lethality.

\section{Introduction}

Valproic acid (2-propylvaleric acid, 2-propylpentanoic acid or n-dipropylacetic acid), derived from valeric acid (produced naturally by valerian, Valeriana officinalis), was first synthesized in 1882 by Burton (Chateauvieux et al., 2010). It is a branched, short-chain fatty acid, forming a clear liquid at room temperature, with a half-life of 9 to 16 hours. For nearly a century, this molecule has been used as a "physiologically inert" solvent for organic compounds. It was in 1963, during a study focused on molecules with potential anti-convulsive activity, in which valproic acid (VPA) was used as a molecular carrier, that the pharmacological activity of VPA has been demonstrated: VPA prevented convulsions induced by pentylenetetrazol in rodents (Chateauvieux et al., 2010). After its introduction in the United States in 1978, VPA enjoyed enormous popularity as both a broad-spectrum anticonvulsant and a mood stabilizer. Valproic acid (VPA) or valproate quickly became the most prescribed antiepileptic drug, with a broad spectrum of use against various forms and several associated syndromes (Thorsten et al., 2008). The influence of VPA on murine fertility and on offspring has been well reported: VPA decreases the fertility rate by $25 \%$ and decreases the number of foetus (Verrotti et al., 2016; Ubeda-Martin et al., 1998). Prospective and retrospective studies demonstrate that VPA is a human teratogen. It increases the risk of major abnormalities by about three times compared to other antiepileptics (Genton et al., 2006; Ornoy at al., 2009). Comparative studies show that while other antiepileptics increase the risk of malformation from 2.9 to $3.6 \%$, the risk of the congenital malformation obtained with VPA is between 6.2 and 7.6\% (Harden and Sethi, 2008). These disorders generally include spina bifida, and more rarely anencephaly, cardiac and craniofacial abnormalities, limb malformations and intrauterine growth delay (valproate syndrome) (Nanau and Neuman, 2013; Genton et al., 2006; Ibrahim, 2012). Children with valproate syndrome in general have developmental or communication trouble, such as autism spectrum disorder or decreased verbal intelligence (Ornoy, 2009). 
The first cases suggesting an association between the use of VPA and the occurrence of congenital malformations had been published for more than 40 years, reporting cleft lip and some other anomalies in 6 children exposed in utero to antiepileptics (Tomson and Battino, 2005). Later, prospective studies distinguished the role of VPA in the occurrence of foetal malformations (Tomson and Battino, 2005). Moreover, forms of encephalopathies associated with VPA have been described, as a direct toxic effect of VPA, with high concentrations of valproate or alterations in renal function (Lheureux et al., 2005; Cuturic and Abramson, 2005; Rath et al., 2005; Gerstner et al., 2006). Encephalopathy is often found in patients with genetic abnormalities of metabolism but also without known genetic abnormalities (Longin et al., 2002).

Experimentally, data have reported evidence of 'autism-like' behavior in patients after prenatal exposure to VPA (Schneider \& Przewlocki, 2005). Major malformations were observed in young rats from female treated with VPA during gestation. Other studies have reported delays in intra-uterine development (Ardinger et al., 1988; Christianson et al, 1994). These observations were based on behavioral, histological and molecular criteria. The objective of the present study was to investigate the effects of perinatal toxicity of treatment with AVP in non-pregnant adult rats and offspring.

\section{Material and methods}

\subsection{Animals}

Adult male and female rats, weighing between 135 and 180 grams, from the animal facility of the Faculty of Health Sciences of the University Marien NGOUABI of Brazzaville, were used. They were raised in polypropylene cages, at an ambient temperature of $25^{\circ} \mathrm{C}$ and a $12 \mathrm{~h} / 12$ light/dark cycle, with free access to water and food. All the experiments were conducted in compliance with Directive 2010/6106 / EU, relating to the protection of laboratory animals (Hartung, 2010).

\subsection{Pharmacological treatments}

Valproic acid was dissolved in distilled water. The rats were divided into 3 groups of 5 animals each and treated orally and daily for 30 days: distilled water $(5 \mathrm{ml} / \mathrm{kg})$, valproic acid 200 and $400 \mathrm{mg} / \mathrm{kg}$. Male rats were used as a breeder and remained isolated, without any treatment until they were mated and used as a breeder.

\subsection{Mating and collection of reproduction data}

24 hours after the end of the administrations, each treated animal was placed in monogamous mating with a breeding male. After mating and gestation, the zootechnical data were recorded and the sensorimotor development of the young rats was monitored during the first 28 days (D28) of life.

Zootechnical variables assess were the following:

- duration of gestation ;

- $\quad$ live litter of animal ;

- $\quad$ average number of deaths per litter of animal;

- $\quad$ average lifespan of young rats before D28.

\subsection{Weight evolution of young rats}

It was made by weighing the rats daily, from birth up to PN28, using an analytical balance of the EU-C7500P T LCD type.

\subsection{Overturning reflex}

This test is based on the principle that an animal placed in a position of imbalance or after a fall turns around to regain its normal quadrupedal position. The test took place on a horizontal board. Each animal was evaluated from the 3rd to the 5th postnatal day (PN). The duration of the test was limited to 2 minutes. The time took to the animal to recover on its four legs was counted.

\subsection{Gripping reaction}

Used to assess the grabbing reflex and thus estimate the strength and muscle tone of the animal. The slightly modified method reported by Gelly et al. (1979) was used. Briefly, a wire mesh plate $(12.5 \times 12.5 \mathrm{~cm}$, mesh size: $3 \mathrm{~mm})$ attached to a manual axis, capable of making a full revolution in 45 seconds was used. An index, placed behind the movable plate, made it possible to locate its position in relation to the vertical at any time of the rotation. A cotton mattress was placed under the device to cushion animal falls. The test was run from PN4 to PN6. Each animal was initially placed on the tray in a horizontal position. The motor is then activated, which causes the rotation of the plate and the sliding of the animal with the consequence of the triggering of the reaction of gripping the wire mesh which makes it possible to avoid the fall. The test stopped when the animal could no longer hold on and fell off the platform. The performance of the animal is estimated by the angle of inclination reached before the fall. The young rat passes the test when it manages to remain gripped at least until the first passage of the vertical platform, ie an angle of $90^{\circ}$.

\subsection{Cliff avoidance}

Signifiant literally "avoidance of the cliff", this test evaluates the avoidance response of the animal relative to the vacuum. This reflex involves the muscle strength and coordination of the front and rear limbs of the young rat. The animal is initially placed at the edge of the paving stone, the head and front legs in the air. The apprehension of the fall pushes him then to try to move away from the edge, either by moving back, or by carrying out a rotation to the right or to the left to try to recover entirely on the block of wood. Each animal was tested in two consecutive trials. Each test is limited to 2 minutes.

The material used to trigger this reaction was made of a wooden block measuring $20 \mathrm{x} 10 \mathrm{~cm}$ and a cotton mattress intended to receive the animal in the event of a fall. The test was performed postnatal, at PN5 and PN7. 
The time taken by the animal to be completely on the block (the head and all four legs) was then noted. Each day, only the best performance is kept for data analysis.

\subsection{Antigravity reaction}

Used to assess a motor reaction involving the coordination of the forelegs and the maturation of structures of the vestibular system in animals. A board $(45 \times 40 \mathrm{~cm})$, inclined $20^{\circ}$ from the horizontal so that the animal does not slip, is used for this test. Submitted from PN8 to PN10, at the start, each rat is placed with the head facing down on the inclined plane. He then undertakes by rotational movements, initiated from the head, to reestablish himself normally in space that is to say with the head pointing upwards. The passage to the horizontal (rotation of $90^{\circ}$ ) constitutes for the young rat the moment of maximum imbalance, where all of its weight rests on the lowest foreleg. The animal passes this test when it performs a rotation of $180^{\circ}$ with respect to its initial position, the duration of the test being fixed at 2 minutes. The time taken by the animal to complete a U-turn is noted. The percentage of success in the test is calculated for each of the groups.

\subsection{Eye opening}

The development index is determined by observing the opening of eye. The animal is observed daily from PN11, until it has fully opened both eyes, generally up to PN17. On the day an animal has both eyes fully open, it is given a score of 1 . 1 point was attributed to the opening of each eye (Roullet et al, 2010).

\subsection{Locomotor coordination test}

The locomotor coordination test is based on a complex motor test and performed before weaning. Broken down into several stages, it allows the young rat to confront different exercises requiring a good sense of balance, coordination of the four limbs and significant physical effort. The device consists of a cylindrical container $(\mathrm{h}: 50 \mathrm{~cm}$, diameter: $25 \mathrm{~cm}$ ) filled with water up to mid-height. A threaded rod (diameter: $8 \mathrm{~mm}$ ), immersed in water, emerges from the center of the tank. At $35 \mathrm{~cm}$ above the water level, a platform is fixed on the threaded rod. The rodent is deposited in the water. While swimming, he will find the threaded rod, hang on to it and climb it until he reaches the platform, where he will be able to rest. Usually, only rats that use their four paws in a coordinated fashion pass this test. The animal may fall during the ascent if it cannot properly grip the rod. Most of the rats then undertake a new attempt, the entry into the water constituting an aversive situation for them. Another risk of falling exists during the transition between the threaded rod and the platform which requires good coordination between the front and rear legs. The rodent succeeds by the time it is fully recovered on the platform. The duration of the test is limited to 4 minutes.

The event is broken down into three stages, each of them being timed:

- $\quad$ swimming time: cumulative time spent in the water,

- climbing time: cumulative climbing time of the rod, from the moment the animal clings to it in the water until it reaches the level of the platform,

- recovery time on the platform : time taken for the animal to recover on the platform, from the moment it is at the top of the rod.

The number of possible falls can also be noted. Because an animal that falls during the test may have to perform several climbs, the swimming and rod climbing times of its different attempts are cumulative. However, important differences in swimming time can be observed between the animals, the encounter with the rod being relatively hazardous on the 1 st test. A percentage of success is also calculated for each group during the three days of testing.

\subsection{Suspension test}

Considered a physical resistance test, performed before PN16, while the animals are still blind, only muscle strength influences the performance of young rats. A wire (diameter: $0.5 \mathrm{~mm}$ ) is stretched between the two uprights of a frame (1: $40 \mathrm{~cm})$ at $20 \mathrm{~cm}$ from the ground. A cotton mattress is placed on the floor of the device to cushion animal falls. Animals were tested only at PN10. To do this, they have to grasp the metal wire by their front legs. A gripping reaction takes place immediately upon contact with the wire. The test begins when the rat has correctly grasped the wire with both forelegs and does not stop until it falls. The time during which the animal remains suspended from the wire is measured.

\subsection{Statistical analyzes}

The results are expressed as the mean \pm standard error of the mean (esm). Statistical analysis was performed using the test $t$ of Student with GraphPad Prism software (San Diego, CA, USA). The significance level corresponds to $\mathrm{p}<0.05$.

\section{Results}

\subsection{Reproduction data}

Female rats treated with valproic acid had a higher litter death rate than control animals, with $4.6 \pm 1.14(\mathrm{p}<0.001)$ and $3.00 \pm 1.22(\mathrm{p}$ $<0.001$ ) respectively for the VPA 200 and $400 \mathrm{mg} / \mathrm{kg}$. The case fatality rate was $41.17,100$ and $68.75 \%$ respectively for the control animals, AVP 200 and VPA $400 \mathrm{mg} / \mathrm{kg}$. The prolificacy rate of the animals treated with VPA was statistically different from that of the control animals. This rate was $100 \pm 0.00,57.8 \pm 4.97$ and $83.2 \pm 4.86$, respectively for CTRL, VPA 200 and $400 \mathrm{mg} / \mathrm{kg}$. The results obtained also show a statistically significant difference in the lifespan of the rats at PN28. However, no significant difference in mean litter was observed. These results are shown in Table I.

Table 1: Effects of Valproic Acid on Reproductive Parameters

\begin{tabular}{llll}
\hline Settings & ED $10 \mathrm{ml} / \mathrm{kg}$ & AVP $200 \mathrm{mg} / \mathrm{kg}$ & AVP 400 mg / kg \\
\hline Duration of gestation & $20.8 \pm 0.83$ & $20.8 \pm 0.83^{\text {(NS) }}$ & $20.8 \pm 0.83^{\text {(NS) }}$ \\
Living litter & $5.00 \pm 1.58$ & $4.6 \pm 1.14^{\text {(NS) }}$ & $4.00 \pm 1.22^{\text {(NS) }}$ \\
Average deaths per litter & $1.4 \pm 0.54$ & $4.6 \pm 1.14^{* * *}$ & $3.00 \pm 1.22^{* *}$
\end{tabular}




\begin{tabular}{llll} 
Case fatality rate\% at D28 & 41.17 & 100 & 68.75 \\
Raccoon lifespan & $28.0 \pm 0.00$ & $10.2 \pm 1.48 * * *$ & $17.6 \pm 2.60 * * *$ \\
\hline
\end{tabular}

The results are expressed as the mean \pm standard error. $(* *): \mathrm{p}<0.01 ;(* * *): \mathrm{p}<0.001$ by student's $\mathrm{t}$ test. ED: distilled water; AVP: valproic acid ; PN : postnatal day.

\subsection{Observation of malformations}

Abnormalities were observed in the litters of animals treated with valproic acid at doses of 200 and $400 \mathrm{mg} / \mathrm{kg}$. These abnormalities were represented by bilateral abutment of necrosis (Figure 1) and an unilateral adactili (Figure 2), or total absence of members (picture not reported).
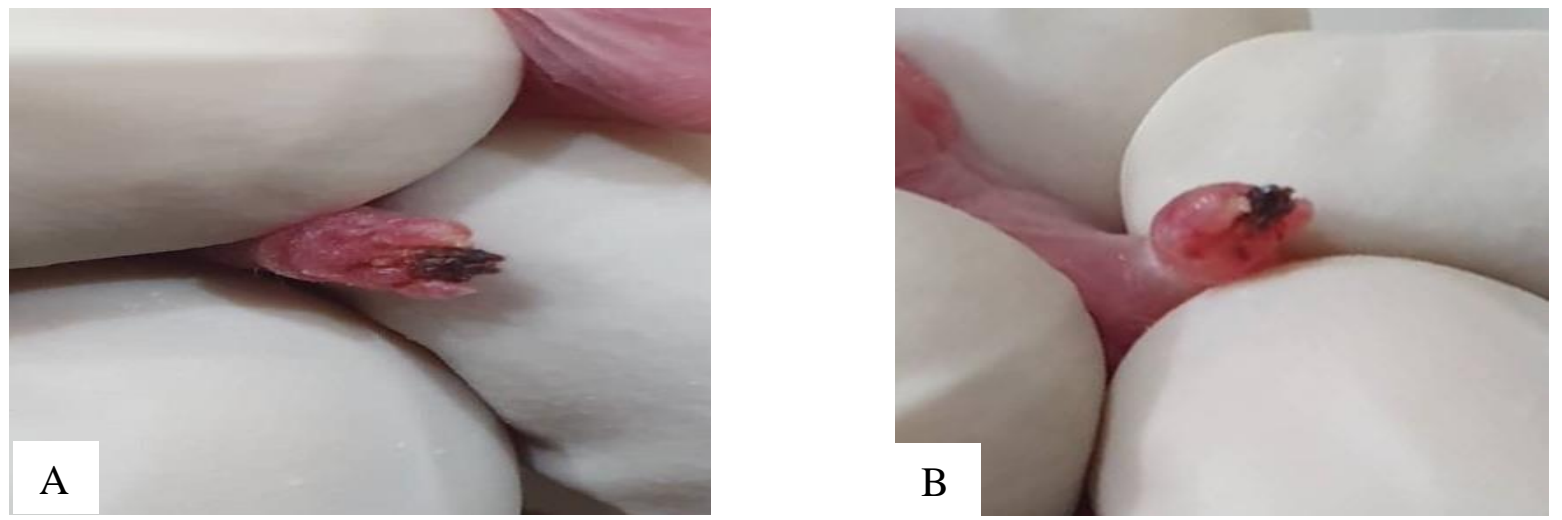

Fig. 1: (A) and (B) Cute Necrosis Recorded in the Group of Animals Derived from Rats Treated with Valproic Acid.
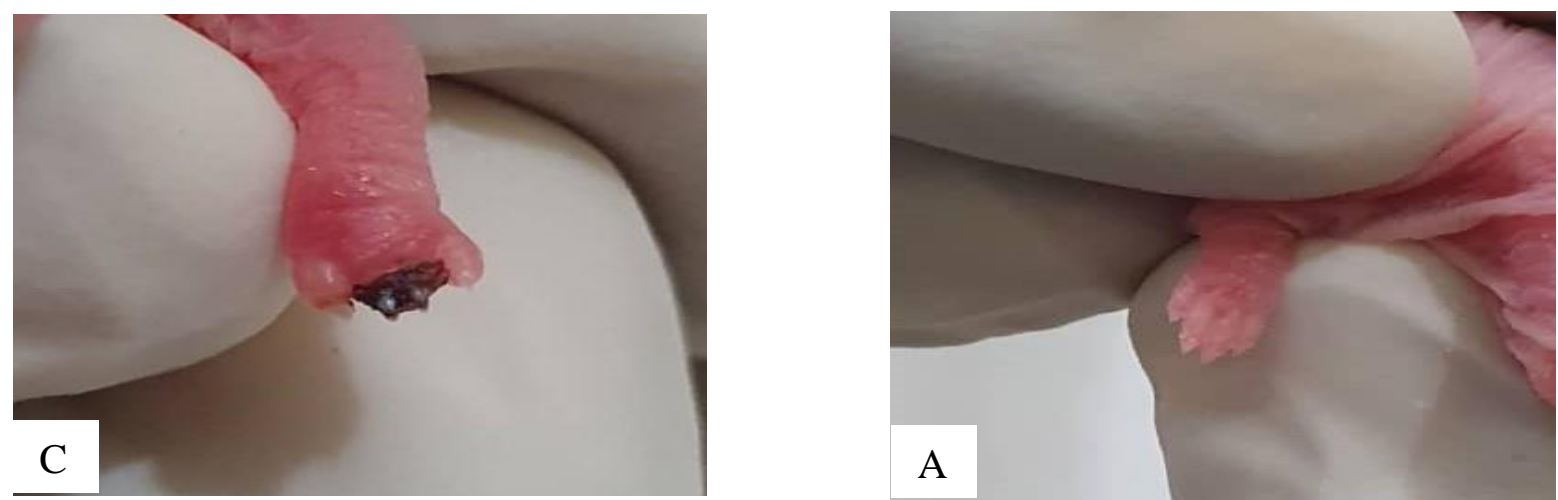

Fig. 2: Photograph of a Adactilia Recorded Unilateral Binds in the Group of Animals from Rats Treated with Valproic Acid (C) and a Normal Paw (D).

\subsection{Weight evolution of rats}

Figure 3 shows the evolution of the weight of the rats. The results show a significant increase in the weight gain of the animals from PN21 with VPA $400 \mathrm{mg} / \mathrm{kg}$. The weight gain was less marked in the offspring of rats treated with VPA at a dose of $200 \mathrm{mg} / \mathrm{kg}$, until the end of the observations.

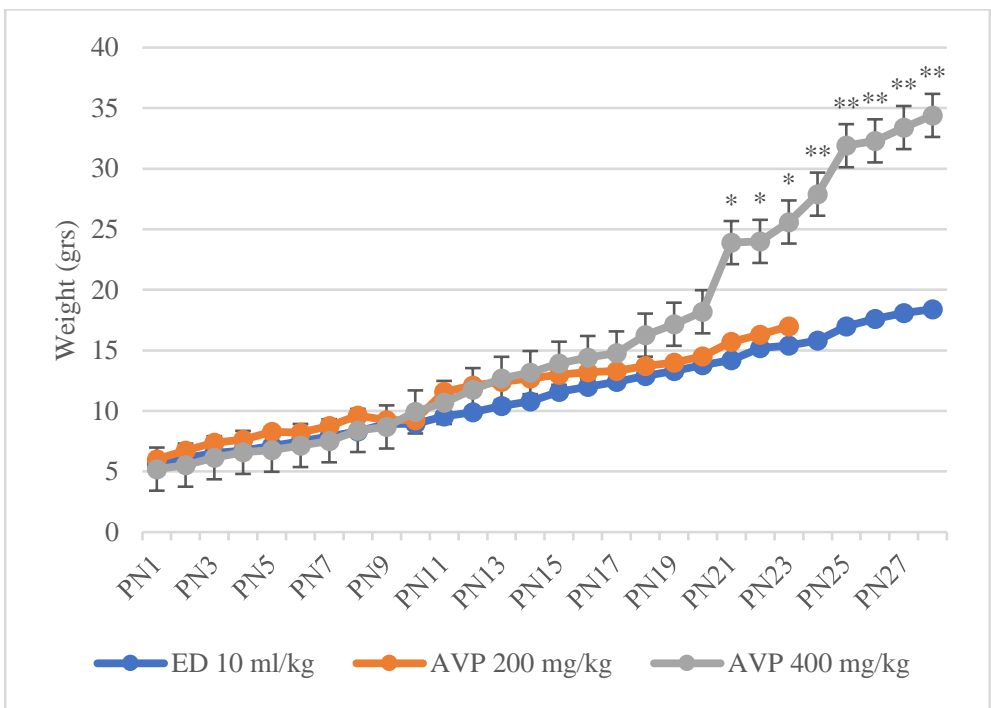

Fig. 3: Weight Evolution of the Young Rats. The Results Are Expressed as the Mean \pm Standard Error. (*): $\mathrm{P}<0.05 ;(* *)$ : $\mathrm{P}<0.01$ by Student's T Test. ED: Distilled Water; AVP: Valproic Acid. 


\subsection{Rollover reflex}

Animals in the VPA 200 and $400 \mathrm{mg} / \mathrm{kg}$ groups exhibited an increase in the turnaround time observed at PN3. However, this increase is only significant in the VPA $200 \mathrm{mg} / \mathrm{kg}$ group at PN3 ( $<<0.01)$. These results are shown in Table II.

Table 2: Effects of Valproic Acid on the Turnaround Time Performed by the Rats

\begin{tabular}{|c|c|c|c|c|}
\hline \multirow{2}{*}{\multicolumn{2}{|c|}{ Reversal reaction }} & \multicolumn{3}{|l|}{ Lots } \\
\hline & & $\mathrm{ED} 10 \mathrm{ml} / \mathrm{kg}$ & AVP $200 \mathrm{mg} / \mathrm{kg}$ & AVP $400 \mathrm{mg} / \mathrm{kg}$ \\
\hline \multicolumn{5}{|l|}{ PN3 } \\
\hline & delay (sec) & $6.6 \pm 0.26$ & $8.00 \pm 0.31 * *$ & $7.4 \pm 0.29^{(\mathrm{NS})}$ \\
\hline & success $(\%)$ & 100 & 72 & 87 \\
\hline \multicolumn{5}{|l|}{ PN4 } \\
\hline & delay (sec) & $5.4 \pm 0.57$ & $6.2 \pm 0.37^{(\mathrm{NS})}$ & $4.9 \pm 0.29^{(\mathrm{NS})}$ \\
\hline & success $(\%)$ & 100 & 90.9 & 93 \\
\hline \multicolumn{5}{|l|}{ PN5 } \\
\hline & delay (sec) & $4.0 \pm 0.31$ & $3.7 \pm 0.20^{(\mathrm{NS})}$ & $3.6 \pm 0.18^{(\mathrm{NS})}$ \\
\hline & success (\%) & 100 & 98 & 100 \\
\hline
\end{tabular}

The results are expressed as a mean \pm standard error for the delay variable and as a mean percentage for the success variable. ( $* *): \mathrm{p}<0.01$, (NS): not significant by the student's t test $(n=4$ rats). ED: distilled water; AVP: valproic acid; PN: postnatal day; $\%$ : percentage.

\subsection{Gripping reaction}

The offspring from the females of the VPA $200 \mathrm{mg} / \mathrm{kg}$ batch showed a significant decrease in the angle of inclination in the grabbing test, throughout the tests. This degree was $67.75 \pm 1.03(\mathrm{p}<0.01), 73.5 \pm 0.86(\mathrm{p}<0.001)$ and $81.5 \pm 1.84(\mathrm{p}<0.01)$, respectively at PN4 5 and 6. These results are summarized in Table III.

Table 3: Effects of Valproic Acid on the Degree of Tilt in the Grip Test

\begin{tabular}{|c|c|c|c|}
\hline Gripping reaction & $\begin{array}{l}\text { Lots } \\
\text { ED } 10 \mathrm{ml} / \mathrm{kg}\end{array}$ & AVP $200 \mathrm{mg} / \mathrm{kg}$ & AVP $400 \mathrm{mg} / \mathrm{kg}$ \\
\hline \multicolumn{4}{|l|}{ PN4 } \\
\hline angle $\left({ }^{\circ}\right)$ & $72.25 \pm 0.85$ & $67.75 \pm 1.03 * *$ & $69.25 \pm 2.17 *$ \\
\hline success $(\%)$ & 48 & 35 & 48 \\
\hline \multicolumn{4}{|l|}{ PN5 } \\
\hline angle $\left({ }^{\circ}\right)$ & $80.5 \pm 0.95$ & $73.5 \pm 0.86^{* * *}$ & $76.25 \pm 2.39 *$ \\
\hline success $(\%)$ & 76 & 73 & 71 \\
\hline \multicolumn{4}{|l|}{ PN6 } \\
\hline angle $\left({ }^{\circ}\right)$ & $91.0 \pm 2.51$ & $81.5 \pm 1.84 * *$ & $83.25 \pm 2.28^{*}$ \\
\hline success $(\%)$ & 73 & 73 & 72 \\
\hline
\end{tabular}

The results are expressed as a mean \pm standard error for the tilt angle variable and as a mean percentage for the success variable. (**): $\mathrm{p}$ $<0.01 ;(* * *): \mathrm{p}<0.001$ by student's t test $(\mathrm{n}=5$ rats). ED: distilled water; AVP: valproic acid; PN: postnatal day.

\subsection{Cliff ovoidance}

Animals in the 200 and $400 \mathrm{mg} / \mathrm{kg}$ VPA groups exhibited an increase in latency prior to recovery in the cliff ovoidance test. However, this increase is only significant at PN5 and PN7, respectively for the AVP $200 \mathrm{mg} / \mathrm{kg}(15.0 \pm 0.70 ; \mathrm{p}<0.05)$ and VPA $400 \mathrm{mg} / \mathrm{kg}(10.0 \pm 3.18$; $\mathrm{p}<0.01$ ), compared to the control batch. These results are shown in Table IV.

Table 4: Effects of Valproic Acid on the Recovery Time of Rats in the Cliff Avoidance Test

\begin{tabular}{|c|c|c|c|}
\hline \multirow{2}{*}{ Cliff ovoidance } & \multirow{3}{*}{$\begin{array}{l}\text { Lots } \\
\text { ED } 10 \mathrm{ml} / \mathrm{kg}\end{array}$} & \multirow{3}{*}{ AVP $200 \mathrm{mg} / \mathrm{kg}$} & \multirow{3}{*}{ AVP $400 \mathrm{mg} / \mathrm{kg}$} \\
\hline & & & \\
\hline PN5 & & & \\
\hline time (sec) & $12.25 \pm 0.85$ & $15.0 \pm 0.70^{*}$ & $12.75 \pm 1.25^{(\mathrm{NS})}$ \\
\hline success $(\%)$ & 39 & 35 & 30 \\
\hline \multicolumn{4}{|l|}{ PN6 } \\
\hline time (sec) & $09.00 \pm 0.75$ & $9.75 \pm 0.85^{(\mathrm{NS})}$ & $13.00 \pm 2.73^{(\mathrm{NS})}$ \\
\hline success $(\%)$ & 58 & 50 & 40 \\
\hline \multicolumn{4}{|l|}{ PN7 } \\
\hline time (sec) & $05.75 \pm 0.62$ & $6.75 \pm 0.62^{(\mathrm{NS})}$ & $10.0 \pm 3.18^{*}$ \\
\hline success $(\%)$ & 82 & 75 & 75 \\
\hline
\end{tabular}

The results are expressed as a mean \pm standard error for the time variable and as a mean percentage for the success variable. $(*): \mathrm{p}<0.05$; (NS): not significant by the student's t test $(n=5$ rats). ED: distilled water; AVP: valproic acid; PN: postnatal day.

\subsection{Antigravity reaction test}

In this test, we found a statistically significant increase $(\mathrm{p}<0.01)$ in the latency time to turn and complete a $180^{\circ}$ return in young rats from females exposed to valproic acid compared to rats from females in the control group. These results are shown in Table V.

Table 5: Effects of Valproic Acid on the Antigravity Reaction Time of Rat. ED : Distilled Water; VPA: Valproic Acid

\begin{tabular}{|c|c|c|c|}
\hline Reaction time & \multirow{2}{*}{$\begin{array}{l}\text { Lots } \\
\text { ED } 10 \mathrm{ml} / \mathrm{kg} \\
\end{array}$} & \multirow{2}{*}{ AVP $200 \mathrm{mg} / \mathrm{kg}$} & \multirow[t]{2}{*}{ AVP $400 \mathrm{mg} / \mathrm{kg}$} \\
\hline PN5 & & & \\
\hline $\begin{array}{l}\text { time (sec) } \\
\text { success }(\%)\end{array}$ & $\begin{array}{l}24.33 \pm 1.45 \\
24\end{array}$ & $\begin{array}{l}28.0 \pm 0.00 * * \\
28\end{array}$ & $\begin{array}{l}27.0 \pm 1.15^{* *} \\
27\end{array}$ \\
\hline
\end{tabular}




\begin{tabular}{lllll}
\hline PN6 & & $19.33 \pm 0.88$ & $24.5 \pm 0.50 * *$ & $21.66 \pm 0.66^{\text {(NS) }}$ \\
& time (sec) & 19 & 24.5 & 21 \\
PN7 & success (\%) & & & $18.00 \pm 057^{* *}$ \\
& time (sec) & $15.00 \pm 1.15$ & $20.33 \pm 1.76^{* *}$ & 12 \\
\hline
\end{tabular}

The results are expressed as a mean \pm standard error for the reaction time variable and as an average percentage for the test success variable. $(* *): \mathrm{p}<0.01$; (NS): not significant by the $\mathrm{t}$ Student test ( $\mathrm{n}=5$ rats). ED: distilled water; AVP: valproic acid; PN: postnatal day.

\subsection{Eye opening}

The ratsborn to females treated with VPA showed a delay in the opening of the eyes compared to the young born to females in the control group. The mean time to opening the eyes (days) was $12.30 \pm 0.48,14.50 \pm 3.21$ and $15.20 \pm 1.03$ respectively for the control groups, VPA 200 and $400 \mathrm{mg} / \mathrm{kg}$. These results are shown in Table VI.

Table 6: Effects of Valproic Acid on the Time It Takes to Open the Eyes of Young Rats

\begin{tabular}{llll}
\hline & Lots & & \\
& ED $10 \mathrm{ml} / \mathrm{kg}$ & AVP $200 \mathrm{mg} / \mathrm{kg}$ & AVP 400 mg / kg
\end{tabular}

The results are expressed as the mean \pm standard error. $(*): \mathrm{p}<0.01$ by student's $\mathrm{t}$ test $(\mathrm{n}=4$ rats). ED: distilled water; AVP: valproic acid.

\subsection{Suspension test}

Figure 4 shows the time taken by the animals in the suspension test. Analysis of the results shows a statistically significant reduction in the suspension time in the rats from females treated with VPA 200 and $400 \mathrm{mg} / \mathrm{kg}(\mathrm{p}<0.01)$ compared to the control group.

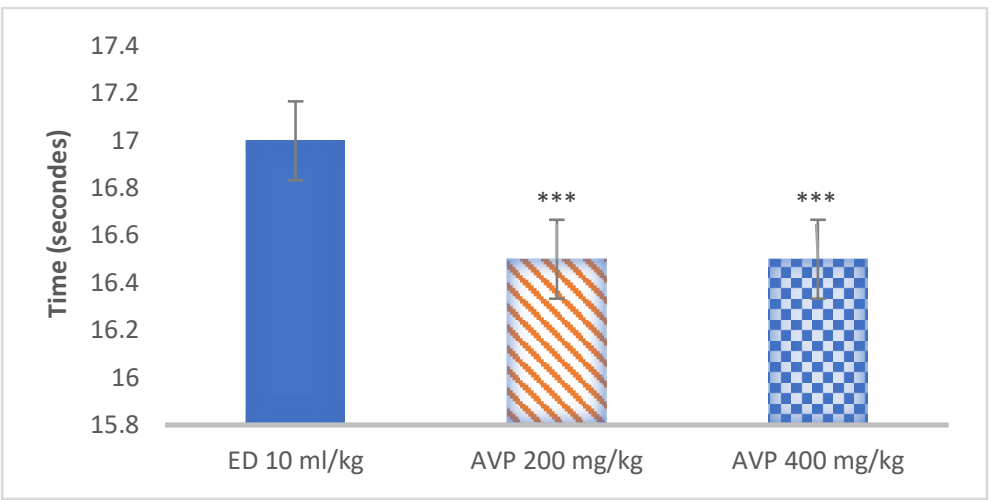

Fig. 4: Effects on the Suspension Time Performed by the Rats. The Results Are Expressed as the Mean \pm Standard Error. (***): P <0.0001; by the T Student Test ( $\mathrm{N}=5$ Rats). ED : Distilled Water; VPA: Valproic Acid.

\subsection{Locomotor coordination test}

Figure 5 shows the results of the locomotor coordination test. Analysis of these results shows that the animals in the VPA 200 and 400 $\mathrm{mg} / \mathrm{kg}$ groups exhibited a significant increase $(\mathrm{p}<0.05)$ in climbing time, swimming time and a decrease in recovery time on the platform, compared to those in the control group.

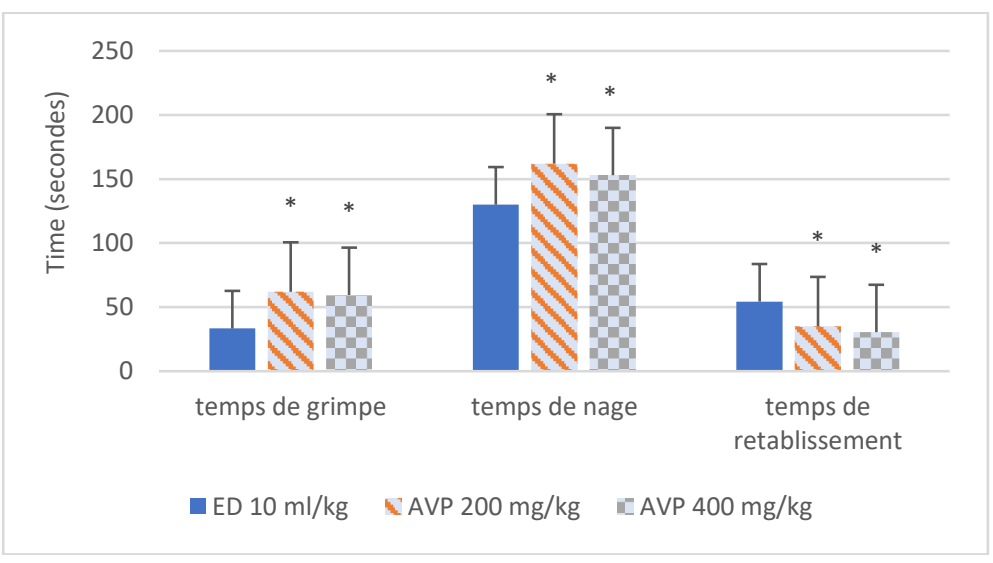

Fig. 5: Effects of AVP on Climbing, Swimming and Recovery Times Performed by Rat. The Results are Expressed as Mean \pm Error. (**): P <0.01; (NS): Not Significant by the T Student Test (N = 5 Rats). ED: Distilled Water; VPA: Valproic Acid. 


\subsection{Open field test}

Table VII shows effects of the treatments on the behavior of the rats in the open field. Analysis of the results shows a statistically significant decrease ( $<$ 0.001) in the grooming time of the animals of the VPA 200 and $400 \mathrm{mg} / \mathrm{kg}$ batches. However, no significant difference was observed in the number of rightings made by the animals in the open field.

Table 7: Effects of Valproic Acid on the Number of Rightings and Grooming Time of Rats in An Open Field.

\begin{tabular}{llll}
\multicolumn{4}{c}{ Table 7: Effects of Valproic Acid on the Number of Rightings and Grooming Time of Rats in An Open Field. } \\
\hline \multirow{2}{*}{ Settings } & Lots & & \\
& ED $10 \mathrm{ml} / \mathrm{kg}$ & AVP $200 \mathrm{mg} / \mathrm{kg}$ & AVP 400 mg / kg \\
\hline Number of adjustments & $21.93 \pm 1.69$ & $21.50 \pm 1.52^{(\text {NS) }}$ & $12.75 \pm 0.35^{*}$ \\
Grooming time $(\mathrm{sec})$ & $49.67 \pm 58.32$ & $12.00 \pm 1.41^{* * *}$ & $10.00 \pm 1.41^{* * *}$ \\
\hline
\end{tabular}

The results are expressed as the mean \pm standard error. $(*): \mathrm{p}<0.05 ;(* * *): \mathrm{p}<0.001 ;$ (NS): not significant by the student's $\mathrm{t}$ test $(\mathrm{n}=4$ rats). ED : distilled water; AVP: valproic acid.

\section{Discussion}

The present study was carried out with the aim of investigating the effects of valproic acid on the maturation of sensorimotor functions in the offspring of female rats treated with AVP. Thus, rats were treated for 30 days with valproic acid, at doses of 200 and $400 \mathrm{mg} / \mathrm{kg}$, then put into mating, and behavioral and neurodevelopmental changes were studied in the offspring. A coherent battery of tests aimed at evaluating the maturation of the motor and sensory systems of the young rat during the first stages of postnatal development has been developed in the laboratory (Gelly 1979). The criteria chosen then made it possible to focus each motor reaction of the animal over a specific period from birth to weaning. The reactions measured were of three types: - complex motor acts: turning reflex, gripping reaction, perception of gravity, coordination of the four limbs, physical strength and resistance to fatigue, - a simple motor reaction: startle following sound stimulation, - a physical index of development: eye opening. Our results validated previous studies which suggest that delays in maturation at different stages of life were associated with exposure to AVP in rats (Roullet et al., 2013).

The results of the zootechnical data showed a significant increase in the number of deaths, a decrease in the prolificacy rate and in the mean lifespan (at PN28) in the VPA groups, compared to the control group. Several malformations have been observed such as necrosis of the stump, adactilia or the total absence of limbs. These abnormalities could be explained by the alterations during the placement of the neural tube. Indeed, it has been reported that the risk of neural tube damage increases by 10 to $20 \%$ with VPA (Tabatabaei and Abbott, 1999). Damage to the neural tube during embryogenesis could also explain the high lethality (100\% before the 28th day of life) observed in the groups of animals derived from rats treated with AVP at $200 \mathrm{mg} / \mathrm{kg}$. On the other hand, the duration of gestation and the live litter were not statistically different from the values observed in the control group.

The results of the tests carried out from birth to PN16 showed differences in the maturation of sensorimotor functions between the animals from rats exposed to VPA and the young from rats in the control group. No birth weight difference was observed between offspring from treated and untreated rats. However, weight monitoring revealed a significant weight gain in the animals of the VPA $200 \mathrm{mg} / \mathrm{kg}$ group from PN21; in comparison with the animals of the control group. Some authors have reported a decrease in body weight gain in rats born to rats exposed to VPA during gestation. Other studies have reported an increase in weight after exposure to AVP, probably linked to an increase in appetite (Gibbons et al., 2019). This difference could be attributed to the period of exposure to VPA.

The rollover test is a test that assesses neuromuscular and locomotor development. Our study showed an increase in the latency put by the rats before performing a complete rollover, associated with a decrease in the percentage of test success, compared to the control group. This difference was significant with the VPA at $200 \mathrm{mg} / \mathrm{kg}$. The variation observed, which may be indicative of a delay in maturation, does not seem to persist since the number of animals which pass the test gradually increases until reaching $100 \%$ at PN5. Other authors have reported that prenatal exposure to VPA causes decreased performance in the rollover test (Roullet et al., 2013).

Moreover, the righting reflex can be described as an arched system made up of neurons from the primary vestibule, neurons from the nuclear vestibule and target motor neurons, which simultaneously require the activation of the cerebullum (Cullen et al., 2012; Mohapatra et al., 2012). The increase in the turnaround time observed at PN3 could be explained by alterations affecting this neural system.

The grip test is used to estimate the strength and muscle tone of the animal. In this study, a decrease in the grip angle reached by the animals of the VPA 200 and $400 \mathrm{mg} / \mathrm{kg}$ groups as well as the percentage of success compared to the control group.

The avoidance test of the cliff (Cliff ovoidance) involves muscle strength and coordination of the front and hind legs of the young rat. In this study, we observed an increase in recovery time in the VPA 200 and $400 \mathrm{mg} / \mathrm{kg}$ groups. At the same time, a reduction in the percentage of success was also observed in the groups of animals derived from females treated with VPA. These results reflect a disturbance in the coordination of movements.

In addition, an increase in the antigravity reaction time of the rats of the VPA 200 and $400 \mathrm{mg} / \mathrm{kg}$ groups. Our results validated several previous works which suggest that there are several alterations at different stages of postnatal development (Roullet et al., 2013).

The opening of the eyes and the righting reflex are considered to be indices of development in rodents (Teitelbaum et al., 1998). Our study showed a delay in opening the eyes in the VPA groups. Although the mechanisms of eye opening in young rats are not fully understood, the neurodevelopmental delay observed with VPA has been reported in several studies and reflects the validity of the construction of the model (Kolozsi et al., 2009).

The opening of the eyes (a developmental index) was delayed in the young rats in the VPA groups compared to those in the control group. Some authors have observed that the size of the litter can influence the date the eyes are opened. Thus, Castellano and Oliverio (1976) observed that young from large litters are likely to open their eyes later than those from smaller litters, due to slower growth. Conversely, Gelly (1979) considers that young from large litters develop aptitudes which would contribute to an earlier maturation of this development index. In our study, no difference in litter size was observed.

The suspension test is considered a test that assesses physical strength. Performed before opening the eyes, this test, only muscle strength is evaluated. In this study, we observed a decrease in the suspension time in animals derived from female rats treated with VPA at the doses studied. These results therefore reflect a decrease in the muscle strength of the young rats of the VPA 200 and $400 \mathrm{mg} / \mathrm{kg}$ groups.

A decrease in performance in motor coordination was also observed in the VPA groups. This drop in performance resulted in an increase in climb time and swim time, associated with a decrease in the time taken for the animals to stand up on the platform.

An open field is used to analyze the spontaneous exploratory activity and curiosity of an animal when faced with a new and spacious environment. This device creates a situation of conflict between the animal's natural tendency to explore this new environment and its 
aversion to open spaces (Hall et al, 1938). In this study, we observed a reduction in the number of straightenings at high dose (400 mg/kg). Grooming time is a marker of anxiety state, with the number of straightenings and the distance covered in the open field (Choleris et al., 2001). The results obtained in this study reflect the presence of an anxious trait in the young rats of the VPA groups.

\section{Conclusion}

Administration of VPA at doses of 200 and $400 \mathrm{mg} / \mathrm{kg}$ to non-pregnant adult rats causes a significant increase in the number of deaths and the mean lifespan (at PN28) in the offspring from these animals. This prenatal exposure reduced the performance of the rats in tests to assess sensorimotor development, thus reflecting abnormalities in sensorimotor development in young rats. Further studies would elucidate the molecular and histological mechanisms of these disturbances.

\section{Author contributions}

Protocol design: LMM, AEMM, CL.

Tests carrying out: AEMM, DNT, CRDD, ENM.

Data analysis and interpretation: LMM, AAA, RBB.

Manuscrit drafting: LMM, CRDD.

Manuscrit correction: AAA, DM.

\section{Conflict of interests}

All the authors declare any conflict of interests.

\section{Acknowledgment}

Author express his deepest gratitude and sincere thanks to Professor Ange Antoine Abena, President of Denis SASSOU NGUESSO University and head of Formation, Research and Biomedical Analysis Laboratory, Faculty of Health Sciences, for his guidancy and helps.

\section{References}

[1] Ardinger HH, Atkin JF, Blackston RD, Elsas LJ, Clarren SK, Livingstone S et al., (1988). Verification of the fetal valproate syndrome phenotype. American journal of medical genetics, 29 (1): 171-85. https://doi.org/10.1002/ajmg.1320290123.

[2] Chateauvieux S, Morceau F, Dicato M, and Diederich M (2010). "Molecular and therapeutic potential and toxicity of valproic acid," Journal of Biomedicine and Biotechnology. ID 479364, 18 p. https://doi.org/10.1155/2010/479364.

[3] Choleris E, Thomas AW, Kavaliers M, and al., (2001). A detailed ethological analysis of the mouse open fifield test: effects of diazepam, chlordiazepoxide and an extremely low frequency pulsed magnetic fifield. Neurosci. Biobehav. Rev, 25: 235-60. https://doi.org/10.1016/S0149 7634(01)00011-2.

[4] Christianson AL, Chesler N, Kromberg JG (1994). Fetal valproate syndrome: clinical and neuro-developmental features in two sibling pairs. Developmental medicine and child neurology, 36 (4): 361-9. PMID: 7512516. https://doi.org/10.1111/j.1469-8749.1994.tb11858.x.

[5] Cuturic M, Abramson RK (2005). Acute hyperammonemic coma with chronic valproic acid therapy. Ann Pharmacother, 39: $2119-22$. https://doi.org/10.1345/aph.1G167.

[6] Genton P, Semah F, and Trinka E (2006). "Valproic acid in epilepsy: pregnancy-related issues," Drug Safety, 29 (1): 1- 21. https://doi.org/10.2165/00002018-200629010-00001.

[7] Gerstner T, Buesing D, Longin E and al., (2006). Valproic acid induced encephalopathy - 19 new cases in Germany from 1994 to 2003 - a side effect associated to VPA-therapy not only in young children. S eizure, 15: 443-8. https://doi.org/10.1016/j.seizure.2006.05.007.

[8] Gibbons C, Hopkins M, Beaulieu K, Oustric P and Blundell JE (2009). Issues in measuring and interpreting human appetite (Satiety / Satiation) and Its contribution to obesity. Curr. Obes. Rep., 8, 77-87. https://doi.org/10.1007/s13679-019-00340-6.

[9] Hall CS (1938). Emotional behavior in the rat. The relationship between emotionality and ambulatory activity. J Comp Psychol, $22: 345-52$. https://doi.org/10.1037/h0059253.

[10] Harden CL and Sethi NK (2008). "Epileptic disorders in pregnancy: an overview," Current Opinion in Obstetrics and Gynecology, 20 (6): 557-62. https://doi.org/10.1097/GCO.0b013e3283184059.

[11] Hartung T (2010). Comparative analysis of the revised Directive 2010/6106 / EU for the protection of laboratory animals with its predecessor 86/609 / EEEEC - t4 report. ALTEX - Alternatives to animal experimentation, 27 (4): 285-303 https://doi.org/10.14573/altex.2010.4.285.

[12] Ibrahim, MA (2012). Evaluation of hepatotoxicity of valproic acid in albino mice, histological and histochemical studies. Life Sci. J., 9 (4): 153-159.

[13] Kolozsi E, Mackenzie RN, Roullet FI, DeCatanzaro D, Foster JA (2009). Prenatal exposure to valproic acid leads to reduced expression of synaptic adhesion molecule neuroligin 3 in mice. Neuroscience, 163 (4): 1201-10. https://doi.org/10.1016/j.neuroscience.2009.07.021.

[14] Lheureux PE, Penaloza A, Zahir S, Gris M (2005). Science review: carnitine in the treatment of valproic acid-induced toxicity - what is the evidence? Crit Care 2005; 9: 431-40. https://doi.org/10.1186/cc3742.

[15] Meador KJ, Baker GA, Browning N et al. , "Cognitive function at 3 years of age after fetal exposure to antiepileptic drugs," New England Journal of Medicine, 2009; 360 (16): 1597-1605. https://doi.org/10.1056/NEJMoa0803531.

[16] Ornoy A (2009). "Valproic acid in pregnancy: how much are we endangering the embryo and fetus?" Reproductive Toxicology, 2009; 28 (1): 1-10. https://doi.org/10.1016/j.reprotox.2009.02.014.

[17] Rath A, Naryanan TJ, Chowdhary GV, Murthy JM (2005). Valproate-induced hyperammonemic encephalopathy with normal liver function. Neurol India, 53: 226-8 https://doi.org/10.4103/0028-3886.16420.

[18] Roullet FI, Lai JK, Foster JA (2013). In utero exposure to valproic acid and autism - a current review of clinical and animal studies. Neurotoxicol Teratol, 36: 47-56. https://doi.org/10.1016/j.ntt.2013.01.004.

[19] Roullet FI, Wollaston L, Decatanzaro D, Foster JA (2010). Behavioral and molecular changes in the mouse in response to prenatal exposure to the anti-epileptic drug valproic acid. Neuroscience, 170 (2): 514-22. https://doi.org/10.1016/j.neuroscience.2010.06.069.

[20] Tabatabaei AR, Abbott FS (1999). Assessing the mechanism of metabolism dependent valproic acid-induced in vitro cytotoxicity. Chem Res Toxicol, 12: 323-30. https://doi.org/10.1021/tx9801864.

[21] Teitelbaum P, Teitelbaum O, Nye J, Fryman J, Maurer RG (1998). Movement analysis in infancy may be useful for early diagnosis of autism. Proceedings of the National Academy of Sciences of the United States of Proc. Natl. Acad. Sci. USA, 95: 13982-13987, Psychology https://doi.org/10.1073/pnas.95.23.13982. 
[22] Thorsten Gerstner $\dagger$, Nellie Bell \& Stephan König (2008). Oral valproic acid for epilepsy - long-term experience in therapy and side effects. Expert Opin. Pharmacother, 9 (2): 1-8 https://doi.org/10.1517/14656566.9.2.285.

[23] Tomson T, Battino D (2005). Teratogenicity of antiepileptic drugs: state of the art. Curr Opin Neurol, 18: 135-40 https://doi.org/10.1097/01.wco.0000162854.67767.06.

[24] Ubeda-Martin N, Alonso-Aperte E, Achon M, Varela-Moreiras G, Puerta J, and Perez de Miguelsanz J (1998). "Morphological alterations induced by valproate and its concomitant administration of folic acid or S-adenosylmethionine in pregnant rats," Nutricion Hospitalaria, 13 (1): $41-9$.

[25] Verrotti A, D'Egidio C, Mohn A, Coppola, and Chiarelli F (2011). "Weight gain following treatment with valproic acid: pathogenetic mechanisms and clinical implications," Obesity Reviews, 2011; 12 (501): 32-43. https://doi.org/10.1111/j.1467-789X.2010.00800.x. 